\title{
Chemical Fingerprinting of Counterfeits of Viagra and Cialis Tablets and Analogues via Electrospray Ionization Mass Spectrometry
}

\author{
Rafael S. Ortiz ${ }^{1,2}$, Kristiane de Cássia Mariotti ${ }^{2}$, Wanderson Romão ${ }^{3,4^{*}}$, Marcos N. Eberlin ${ }^{3}$, \\ Renata P. Limberger ${ }^{2}$, Paulo Mayorga ${ }^{2}$ \\ ${ }^{1}$ Rio Grande do Sul Technical and Scientifical Division, Brazilian Federal Police, \\ Porto Alegre, Brazil \\ ${ }^{2}$ Department of Pharmacy, Federal University of Rio Grande do Sul, Porto Alegre, Brazil \\ ${ }^{3}$ ThoMSon Mass Spectrometry Laboratory, Institute of Chemistry, University of Campinas - \\ UNICAMP, Campinas, Brazil \\ ${ }^{4}$ Department of Chemistry, Federal University of Espírito Santo, Vitória, Brazil. \\ E-mail: wandersonromao@gmail.com \\ Received October 18, 2011; revised November 25, 2011; accepted December 13, 2011
}

\begin{abstract}
Direct infusion electrospray ionization mass spectrometry (ESI-MS) is shown to provide an efficient tech- nique for the investigation of polar composition of forensic tablets for male erectile dysfunction. ESI-MS fingerprinting

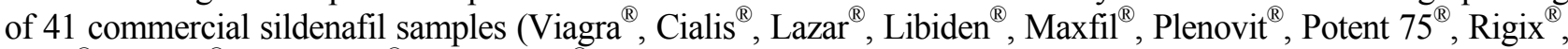
V-50 ${ }^{\circledR}, \operatorname{Vimax}^{\circledR}$, Pramil $75^{\circledR}$ and Pramil ${ }^{\circledR}$ ) and 56 counterfeit samples (Viagra and Cialis) were obtained. The spectra for the authentic Viagra ${ }^{\circledR}$ tablets showed abundant ions exclusively corresponding to the sildenafil (SLD) molecule: $[\mathrm{SLD}+\mathrm{H}]^{+}$of $\mathrm{m} / \mathrm{z} 475$; [SLD $\left.+\mathrm{Na}\right]^{+}$of $\mathrm{m} / \mathrm{z} 497$; and $[2 \mathrm{SLD}+\mathrm{H}]^{+}$of $\mathrm{m} / \mathrm{z}$ 949. The spectra for commercial sildenafil samples also showed predominat SLD ions. Tablets of authentic Cialis ${ }^{\circledR}$ showed mainly ions of $\mathrm{m} / \mathrm{z} 343,365$ and 707 from the lactose molecule (the excipient); as well as a minor ion of $\mathrm{m} / \mathrm{z} 390$ corresponding to the active ingredient tadalafil (TAD) in its protonated form $[\mathrm{TAD}+\mathrm{H}]^{+}$. For counterfeit Cialis samples, however, normally TAD ions of much high abundances was observed, together with ions corresponding to sildenafil analogues such as those of $\mathrm{m} / \mathrm{z} 489$ (homosildenafil) and 505 (hydroxyhomosildenafil). Principal component analysis was applied to ESI-MS fingerprint data, placing samples according to their contents of active ingredients hence authentic and counterfeit samples are easily recognized.
\end{abstract}

Keywords: ESI-MS, Fingerprinting, Counterfeiting, Viagra $^{\circledR}$, Cialis ${ }^{\circledR}$

\section{Introduction}

Sildenafil (SLD) and tadalafil (TAD) are selective inhibitors of phosphodiesterase type-5 (PDE-5) [1] acting therefore as efficient drugs to treat male erectile dysfunction. The two most common commercial formulations containing these active pharmacological ingredients (API) are Viagra ${ }^{\circledR}$ (sildenafil citrate, Pfizer) and Cialis $^{\circledR}$ (tadalafil, Eli Lilly) ${ }^{1}$ and the analysis of their tablets is currently a common practice for many forensic laboratories. Besides the criminal aspect, the illegal trade of these drugs can cause serious health problems due to uncontrolled amounts, low quality and diverse com-

\footnotetext{
${ }^{1}$ The symbol ${ }^{\circledR}$ will be used only in reference to the original medicines.
}

positions. The counterfeiting of inhibitors of PDE-5 has become an important and dangerous problem for pharmaceutical market. Therefore, rapid and secure analytical tools able to control the quality of pharmaceutical formulations are highly desirable.

The identification of SLD or TAD in pure form or in pharmaceutical formulations-including counterfeits have been performed by different analytical techniques such as Raman spectroscopy, nuclear magnetic resonance spectroscopy, Fourier transform infrared spectroscopy, liquid chromatography, mass spectrometry using electrospray ionization or fast-atom bombardment, and X-ray diffractometry [2-8].

Direct infusion electrospray ionization mass spec- 
trometry (ESI-MS) has been shown to provide a fast and robust technique for quality control of complex chemical mixtures such as those of alcoholic [9] and non alcoholic [10] beverages, biodiesel [11], coffees [12], perfumes [13], vegetable oils [14], propolis [15] and drugs of abuse [16]. The use of direct infusion ESI-MS in the chemical characterization of forensic samples of PDE-5 inhibitors seems therefore advantageous, since it would eliminate the need for isolation and prior chromatographic separation, minimizing the time of analysis and interferences. Chemometrics methods applied to ESI-MS data $[17,18]$ could also improve selectivity for secure counterfeit screening.

In this study, ESI-MS in the positive ion mode was shown to provide fast (less than a minute) and secure technique of the forensic analysis of samples of PDE-5 inhibitors. To test this ability, forty one commercial samples $\left(\right.$ Viagra $^{\circledR}$, Cialis $^{\circledR}$, Lazar $^{\circledR}$, Libiden $^{\circledR}$, Maxfil $^{\circledR}$, Plenovit $^{\circledR}$, Potent $75^{\circledR}$, Rigix ${ }^{\circledR}$, V-50 ${ }^{\circledR}$, Vimax ${ }^{\circledR}$, Pramil $75^{\circledR}$ and Pramil ${ }^{\circledR}$ ) and fifty seven counterfeit samples (Viagra and Cialis) were analyzed, and the data subjected to principal component analysis, PCA.

\section{Materials and Methods}

HPLC-grade methanol and formic acid solutions were purchased from Sigma-Aldrich and used with no further purification. Eight authentic samples of Viagra ${ }^{\circledR}$ and Cialis ${ }^{\circledR}$ containing $50 \mathrm{mg}$ of SLD (4) and $20 \mathrm{mg}$ of TAD (4), respectively, were supplied by Pfizer Ltda and Eli Lilly do Brasil Ltda laboratories. The thirty three tablets of different trademarks of foreign origin and fifty six counterfeit samples (Table 1) were provided by the Bra- zilian Federal Police forensic laboratory (Rio Grande do Sul, Brazil).

\subsection{ESI-MS}

An API 2000 Q-Trap LC-MS/MS mass spectrometer from MDS Sciex/Applied Biosystems (Foster City, CA, USA) coupled to a Alliance 2695 Separations Module LC (Waters, Milford Massachusetts, USA) was used. Data acquisition and processing were performed using the Analyst software from Applied Biosystems (Foster City, CA, USA). General conditions were as follows: source temperature of $100^{\circ} \mathrm{C}$, capillary voltage of $3.0 \mathrm{kV}$ and cone voltage of $40 \mathrm{~V}$. The sample preparation consists in dissolution of a small fraction-about $10 \mathrm{mg}$ - of the core of each tablet in a solution containing $40 \mathrm{~mL}$ of methanol and $40 \mu \mathrm{L}$ of concentrated formic acid aqueous solution. ESI-MS was performed with the automatic injection of each sample in the module chromatography (LC) programmed to elute all the soluble components in a single peak. Mass spectra were acquired and accumulated over $60 \mathrm{~s}$ on the range of $\mathrm{m} / \mathrm{z} 50$ to 1000 . Structural analysis of some diagnostic ions was performed by ESI-MS/MS using collision energies varying from 15 to $45 \mathrm{eV}$. The collision gas pressure (argon) was optimized to produce extensive fragmentation of the ions under investigation.

\subsection{Chemometric Treatment}

Multivariate analysis by PCA was performed by running the software STATISTICA, version $7\left(\right.$ StatSoft $\left.^{\circledR}\right)$. The ESI-MS data were compiled to generate a final matrix of

Table 1. Details of seizure samples investigated.

\begin{tabular}{|c|c|c|c|c|c|}
\hline Samples & $\begin{array}{c}\text { Number of } \\
\text { samples seized }\end{array}$ & $\begin{array}{c}\text { Number of } \\
\text { samples analyzed }\end{array}$ & $\begin{array}{c}\text { Register } \\
\text { of seizure }\end{array}$ & Samples & $\begin{array}{c}\text { Number of } \\
\text { samples analyzed }\end{array}$ \\
\hline \multirow[t]{2}{*}{ Viagra $^{\circledR}$} & - & 4 & - & $\operatorname{Lazar}^{\circledR}$ & 3 \\
\hline & 132 & 10 & I & Potent $75^{\circledR}$ & 2 \\
\hline \multirow{2}{*}{ Counterfeit Viagra } & 8 & 1 & II & $\operatorname{Vimax}^{\circledR}$ & 3 \\
\hline & 9 & 7 & IV & Rigix $^{\circledR}$ & 2 \\
\hline \multirow[t]{3}{*}{ Cialis $^{\circledR}$} & - & 4 & - & Plenovit $^{\circledR}$ & 6 \\
\hline & 6 & 1 & $\mathrm{~V}$ & Pramil $^{\circledR}$ & 8 \\
\hline & 7 & 1 & VI & Pramil $^{\circledR} 75$ & 2 \\
\hline \multirow{2}{*}{ Counterfeit Cialis } & 40 & 10 & VIII & Libiden $^{\circledR}$ & 1 \\
\hline & 40 & 9 & IX & & \\
\hline
\end{tabular}


97 cases (samples) and 99 variables ( $\mathrm{m} / \mathrm{z}$ values with their respective relative intensities). Only ions with a relative abundance higher than $10 \%$ were considered for the final matrix data. These data were previously mean-centered and auto scaled to variance 1 , ensuring an equal contribution of all variables.

\section{Results and Discussion}

\subsection{ESI(+)-MS Fingerprinting}

A set of 23 Viagra samples classified as authentic (4) or counterfeit (19) termed as I, II, III and IV (Table 1), were analyzed by ESI(+)-MS. Figure 1(a) shows typical ESI(+)-MS obtained for authentic Viagra ${ }^{\circledR}$ tablets. The main ions correspond to the SLD molecule detected in different forms such as [SLD $+\mathrm{H}]^{+}$of $\mathrm{m} / \mathrm{z} 475$; [SLD + $\mathrm{Na}]^{+}$of $m / z$ 497; [2SLD $\left.+\mathrm{H}\right]^{+}$of $m / z 949$, and fragment ions of $\mathrm{m} / \mathrm{z} 377,311,283$ and 99 [19,20]. Therefore, ESI(+)-MS provides, for the methanolic extract, a typical fingerprint data showing mainly SLD ions from the active pharmaceutical ingredient present in standard Viagra $^{(B)}$ samples.

To confirm SLD detection, ESI(+)-MS/MS was performed for the ions of $\mathrm{m} / \mathrm{z} 475$ and 949 (Figures 2(a)-(b)). The collision-induced dissociation (CID) of $[\mathrm{SLD}+\mathrm{H}]^{+}$of $\mathrm{m} / \mathrm{z} 475$ (Figure 2(a)) agrees well with its structure and connectivity, and reported spectra [8]. The ion of $\mathrm{m} / \mathrm{z} 949$ [2SLD $+\mathrm{H}]^{+}$formed, as expected, [SLD + $\mathrm{H}]^{+}$of $\mathrm{m} / \mathrm{z} 475$ as the main fragment (Figure 2(b)).

Figures 1(b)-(e) show ESI(+)-MS spectra for counterfeit Viagra samples (seizures I-IV, Table 1). SDL ions also predominate but for seizures I and II (Figures 1(b)-(c)), the $\operatorname{ESI}(+)-\mathrm{MS}$ detects an ion of $\mathrm{m} / \mathrm{z} 489$ corresponding probably to the protonated molecule of an immediate analogue of SLD. The ESI(+)-MS/MS data for this ion (Figure 2(c)) display fragments similar or the same as those produced by $[\mathrm{SDL}+\mathrm{H}]^{+}$: those of $\mathrm{m} / \mathrm{z} 58$, 70, 84, 99, 254, 283, 297, 313 and 325. This molecule can be attributed to homosildenafil (HSD), being distinguished from another possible isomer, vardenafil, by the absence of an abundant ion of $m / z$ 151 [21]. The presence of analogue species of SLD can result from intentional addition or from inadequate purification.

Figure 1(e) shows the presence of low abundant but unique ions of $\mathrm{m} / \mathrm{z}$ of $221,237,355,429$ and 445 . For sample III, however, a very similar $\operatorname{ESI}(+)$-MS data as that observed for authentic Viagra ${ }^{\circledR}$ samples (Figure 1(d)) was acquired.

Authentic and counterfeit Cialis samples were also analyzed by ESI(+)-MS (Figures 3(a)-(f)). The spectrum for the authentic Cialis ${ }^{\circledR}$ sample (Figure 3(a)) shows a low abundant but diagnostic $[\mathrm{TAD}+\mathrm{H}]^{+}$ion of $\mathrm{m} / \mathrm{z}$ of 390. More abundant ions were attributed to the lactose excipient, that is: [lactose $+\mathrm{H}]^{+}$of $\mathrm{m} / \mathrm{z} 343$; [lactose + $\mathrm{Na}]^{+}$of $\mathrm{m} / \mathrm{z} 365$; and [2lactose $\left.+\mathrm{Na}\right]^{+}$of $\mathrm{m} / \mathrm{z} 707[25,26]$. Cialis tablet are known to contain $20 \mathrm{mg}$ of TAD and $245 \mathrm{mg}$ of lactose.

The structures of the ions of $\mathrm{m} / \mathrm{z} 365,390$ and 779 were investigated by ESI-MS/MS (Figures 4(a)-(b)). $[\mathrm{TAD}+\mathrm{H}]^{+}$of $\mathrm{m} / \mathrm{z} 390$ dissociated as expected from reported data (Figure 4(a)) [21] whereas the protonbonded dimer [2TAD $+\mathrm{H}]^{+}$of $\mathrm{m} / \mathrm{z} 779$ dissociates mainly to $[\mathrm{TAD}+\mathrm{H}]^{+}$of $\mathrm{m} / \mathrm{z} 390$ (Figure $4(\mathbf{b})$ ). For [lactose $+\mathrm{H}]^{+}$of $\mathrm{m} / \mathrm{z} 365$ (Figure 4(c)) also dissociated as expected from reported data $[17,22]$ whereas $[2 \text { Lactose }+\mathrm{Na}]^{+}$forms [lactose $\left.+\mathrm{Na}\right]^{+}$of $\mathrm{m} / \mathrm{z} 365$.

The counterfeit Cialis samples displayed very contrasting and variable spectra (Figures 3(b)-(f)). Seizure $\mathrm{V}$ displayed much more abundant TAD ions which indicate the (potentially harmful) use of higher amounts of the active ingredient. For seizures VI, VIII and IX, however, instead of TAD ions, abundant SLD ions were detected. For seizure VII, both TAD and SDL ions were detected. An ion of quite low abundance $(\mathrm{m} / \mathrm{z} 505)$ was also observed in Figure 3(b) corresponding to another analogue of SLD, namely hydroxyhomosildenafil $(\mathrm{OH}-$ HSD) [23], as confirmed by $\mathrm{ESI}(+)-\mathrm{MS} / \mathrm{MS}$ (Figure 2(d)) [21]. The HSD and OH-HSD analogues display higher pharmacological activity than SLD [24].

For commercial samples-known to be manufactured in neighboring countries as Paraguay and Uruguay-two most typical EASI(+)-MS data were obtained: samples commercialized under the trademarks Lazar ${ }^{\circledR}$, Potent $75^{\circledR}$, Vimax $^{\circledR}$, Maxfil $^{\circledR}$, Rigix $^{\circledR}$, Plenovit $^{\circledR}$ and Pramil ${ }^{\circledR}$ (Figure 5(a)) show only SLD ions whereas samples of Pramil $75^{\circledR}, \mathrm{V}-50^{\circledR}$ and Libiden ${ }^{\circledR}$ (Figure 5(b)) showed also the presence of lactose ions. These drugs are not approved by the National Health Surveillance Agency (ANVISA) to be sold in Brazil, but the ESI(+)-MS data show similar compositions as those of the commercial samples (Figure 1(a)).

\subsection{Chemometry}

ESI(+)-MS data were subjected to chemometric treatment via PCA, Figures 6-7. PCA was used to statisticcally evaluate the performance of ESI-MS fingerprints in classifying of sildenafil citrate and tadalafil samples for quality control purposes. Figures 6 shows PC1 $x$ PC $2 x$ PC3 scores plots, where the 3 first PCs account for $91 \%$ of total variance. Three groups are observed: authentic Viagra ${ }^{\circledR}$, counterfeit Viagra, commercial and some counterfeit Cialis samples containing the SLD molecule form group I; counterfeit Cialis samples containing the TAD molecule form group II; and authentic Cialis ${ }^{\circledR}$ samples form group III. The ions of $m / z$ 707, 475, 412, 390, 


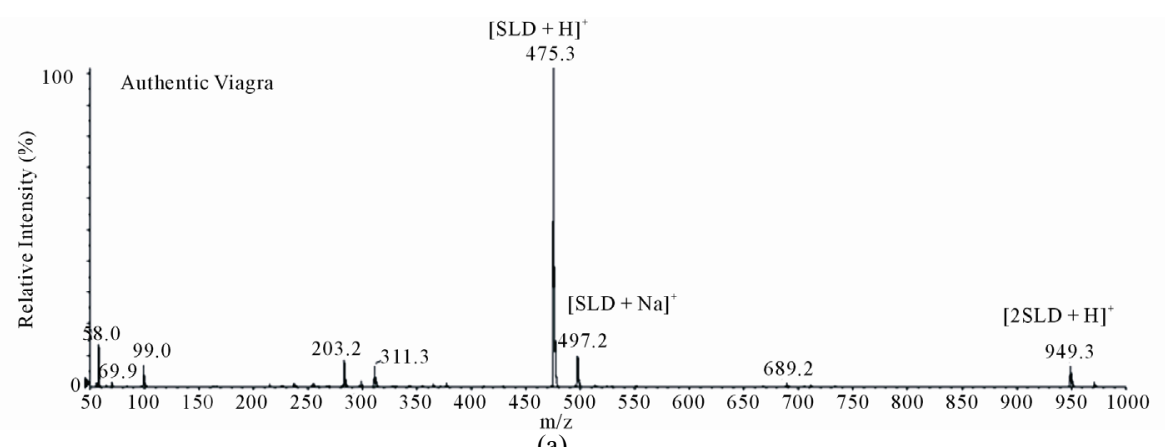

(a)

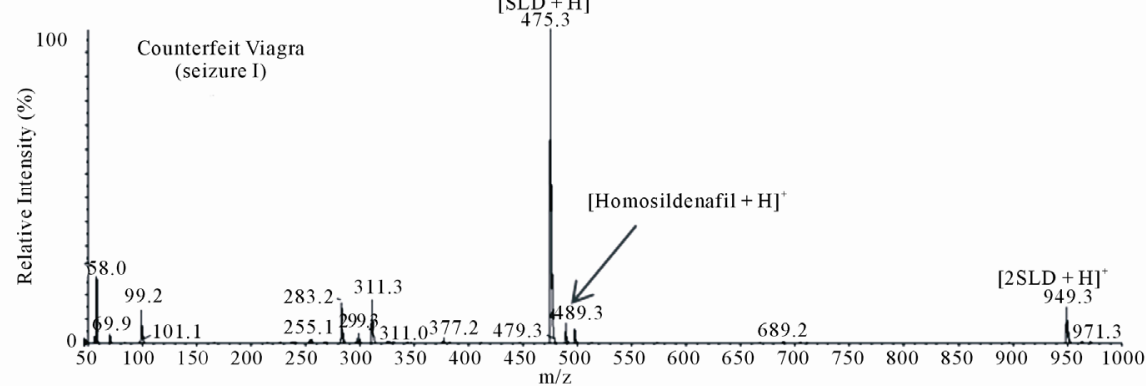

(b)

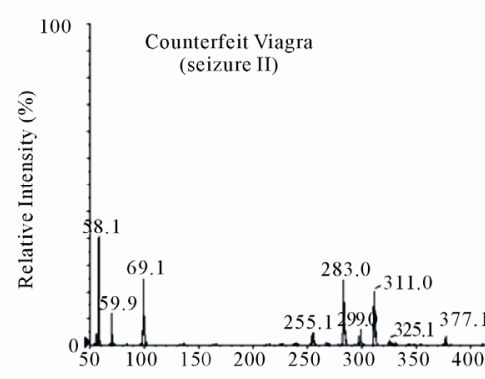

$\left[\begin{array}{c}\mathrm{SLD}+\mathrm{H}] \\ 475.1\end{array}\right.$

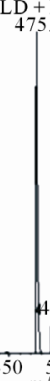

(c)

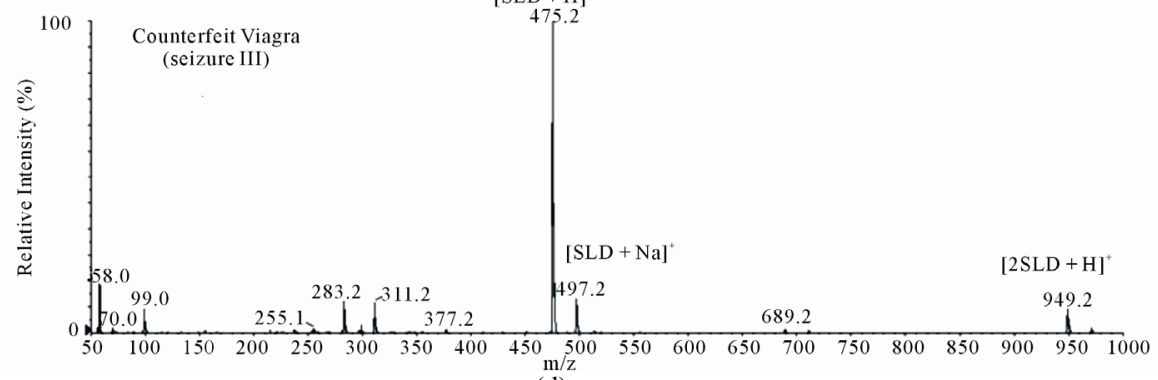

$[\text { Homosildenafil }+\mathrm{H}]^{\dagger}$
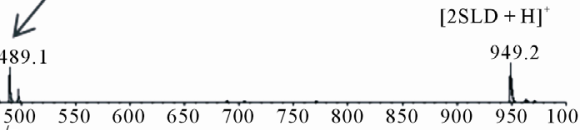

(c)

(d)

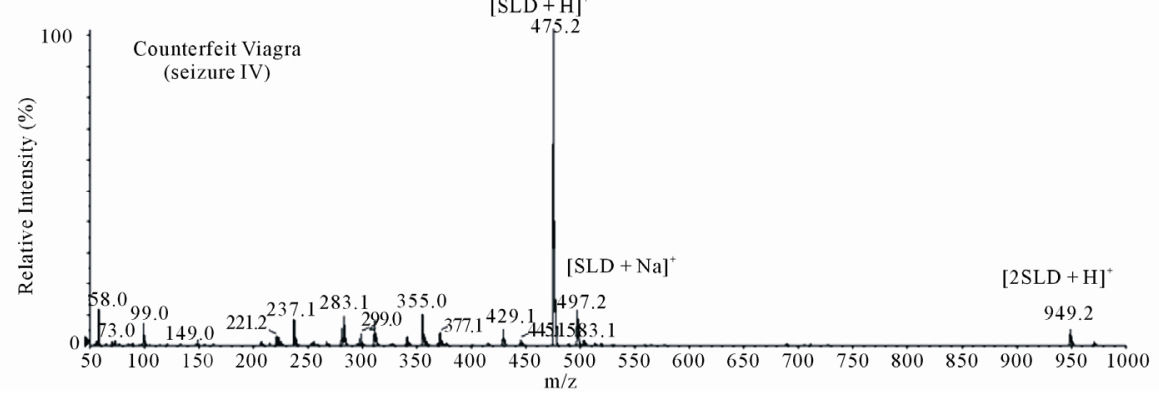

(e)

Figure 1. ESI(+)-MS of representative (a) authentic Viagra ${ }^{\circledR}$ and counterfeit Viagra samples: (b) I, (c) II, (d) III and (e) IV. 


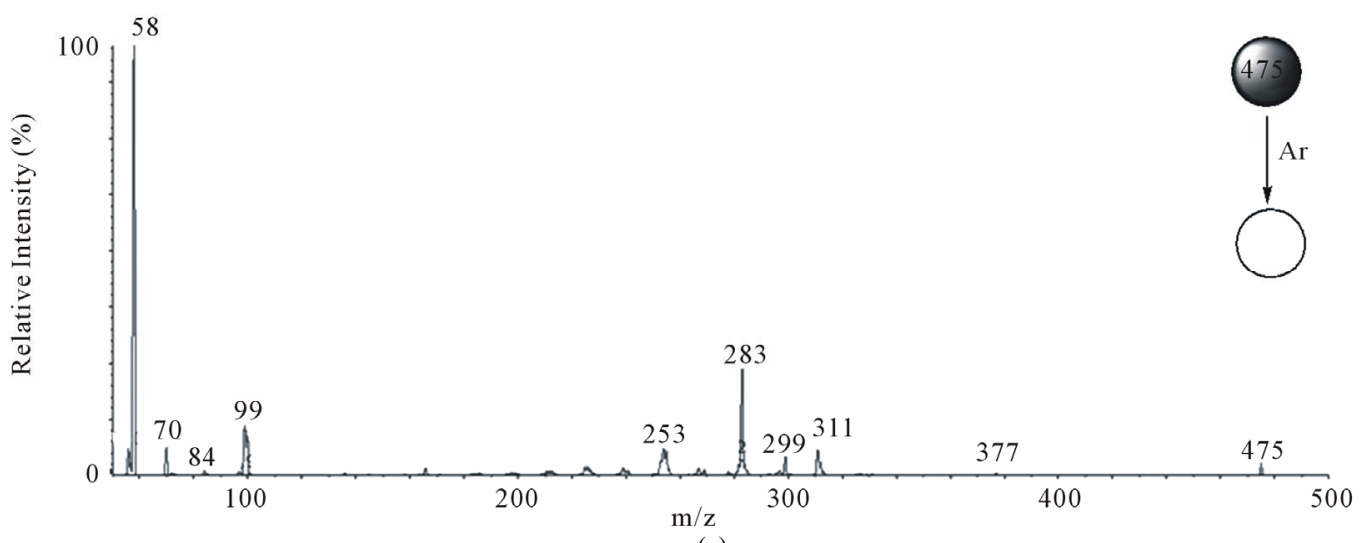

(a)

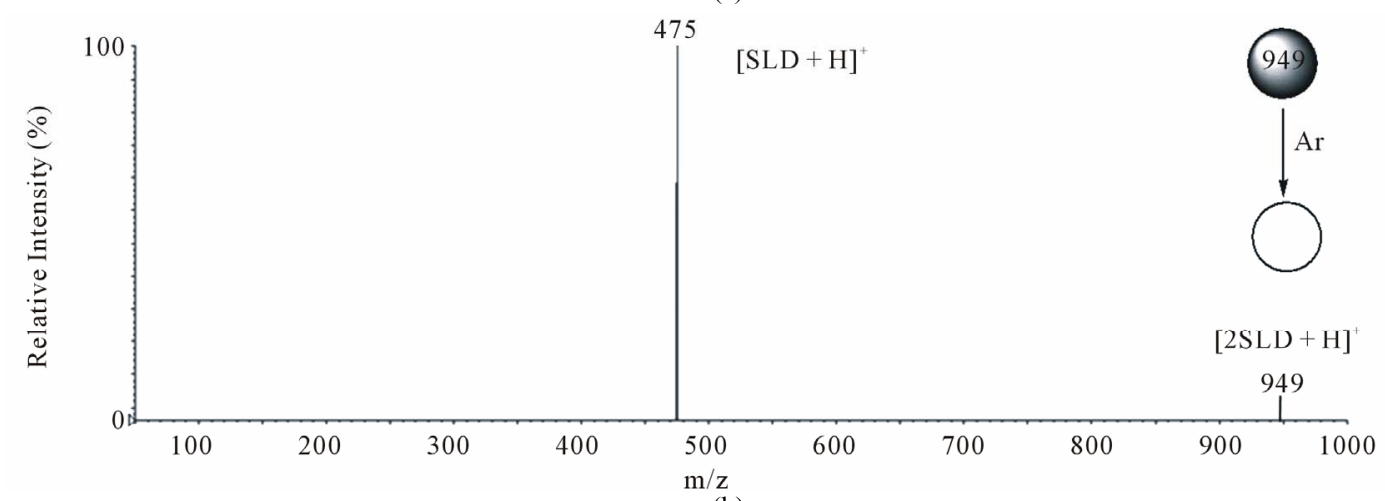

(b)

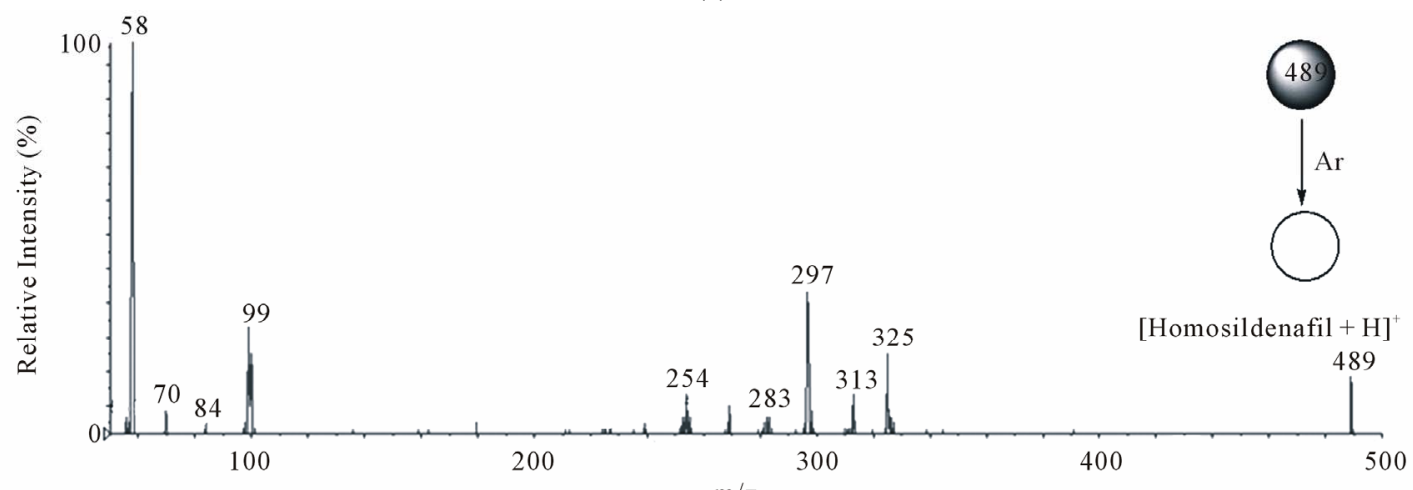

$\mathrm{m} / \mathrm{z}$
$(\mathrm{c})$

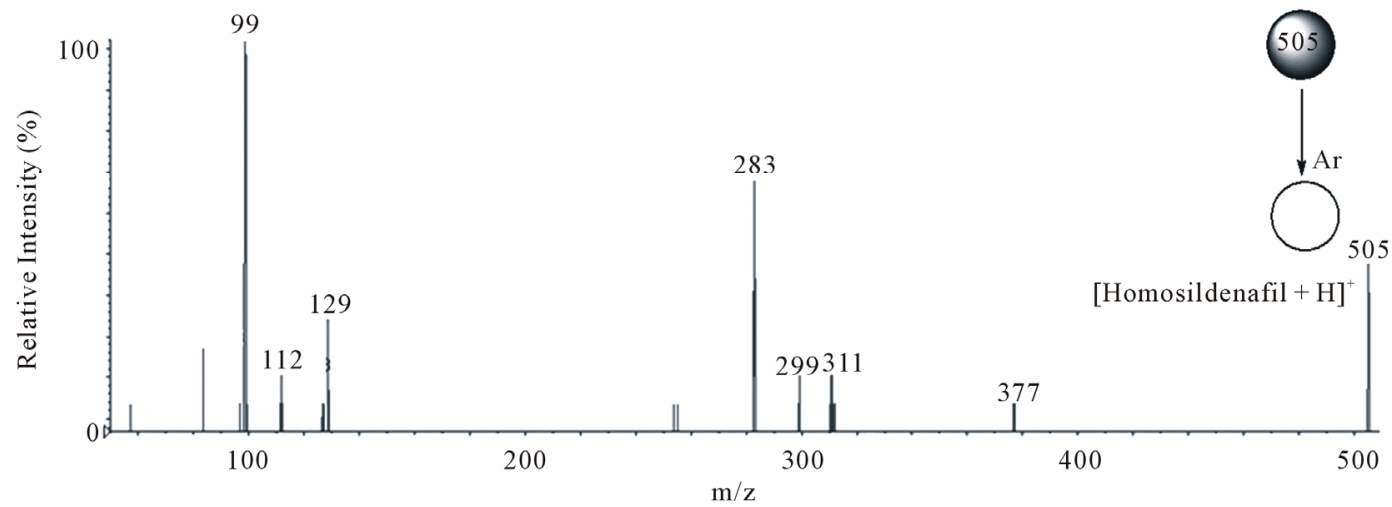

(d)

Figure 2. ESI(+)-MS/MS for some diagnostic ions: (a) [SLD $+\mathrm{H}^{+}$of $\mathrm{m} / \mathrm{z} 475$; (b) $[2 \mathrm{SLD}+\mathrm{H}]^{+}$of m/z 949; (c) [Homosildenafil $+\mathrm{H}]^{+}$of $\mathrm{m} / \mathrm{z} 489$; and (d) $[\text { Hydroxyhomosildenafil }+\mathrm{H}]^{+}$of $\mathrm{m} / \mathrm{z} 505$. 


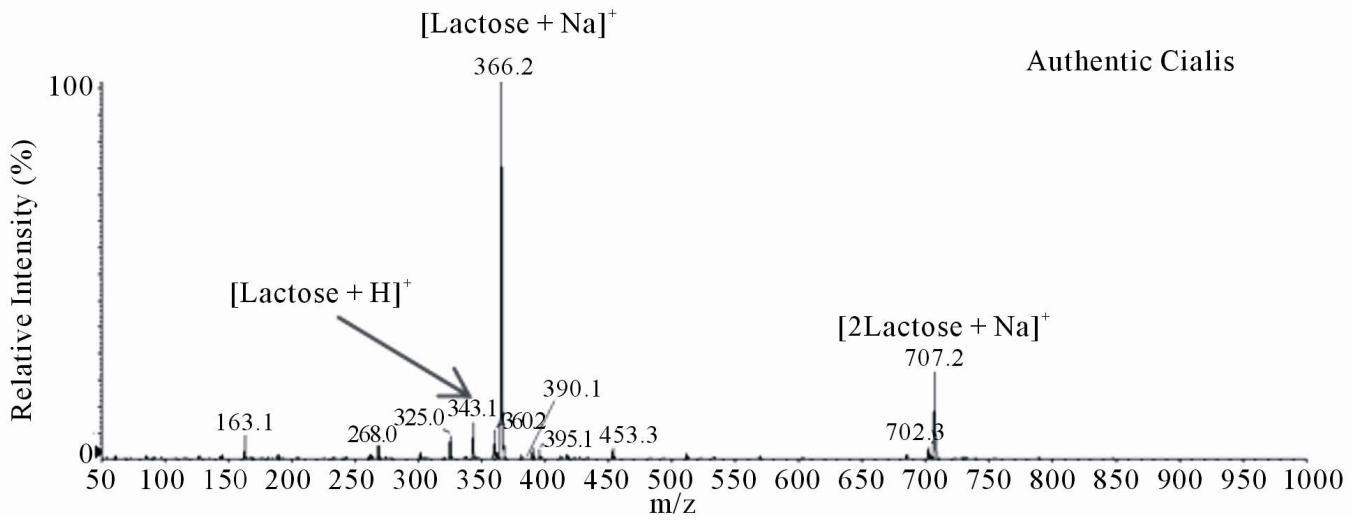

(a)

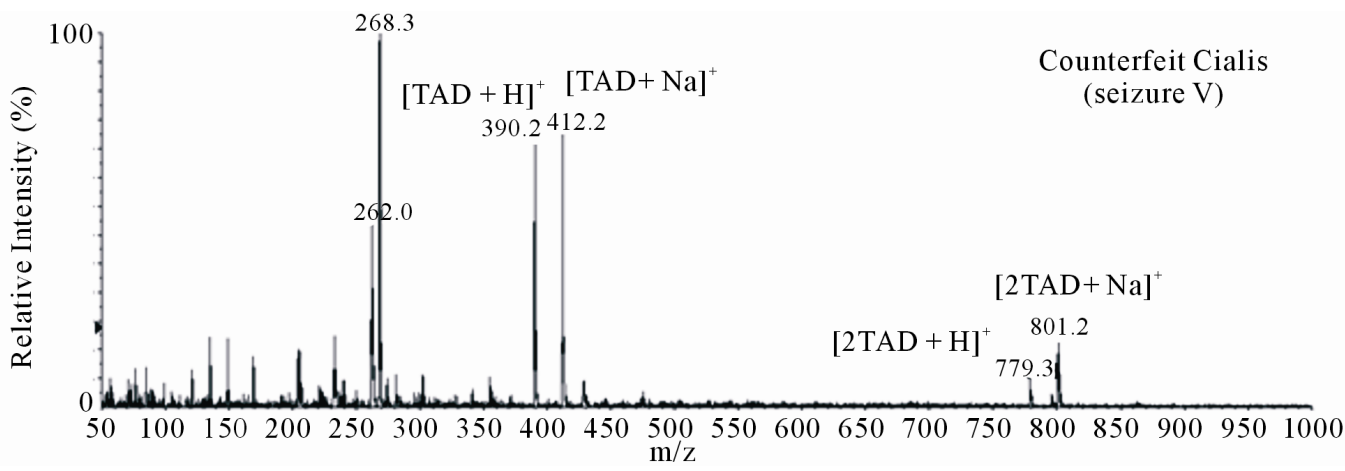

(b)

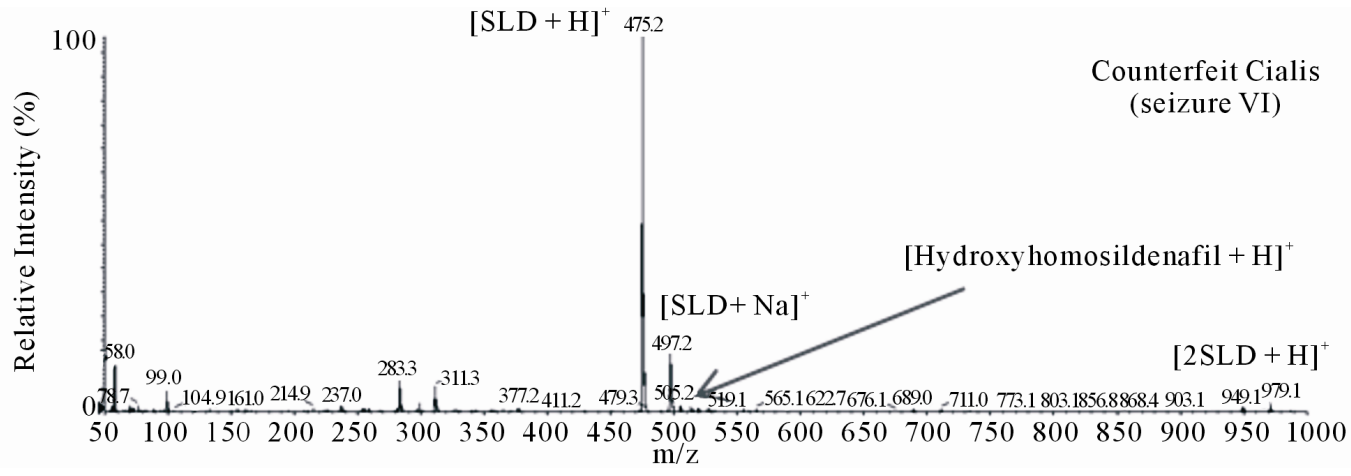

(c)

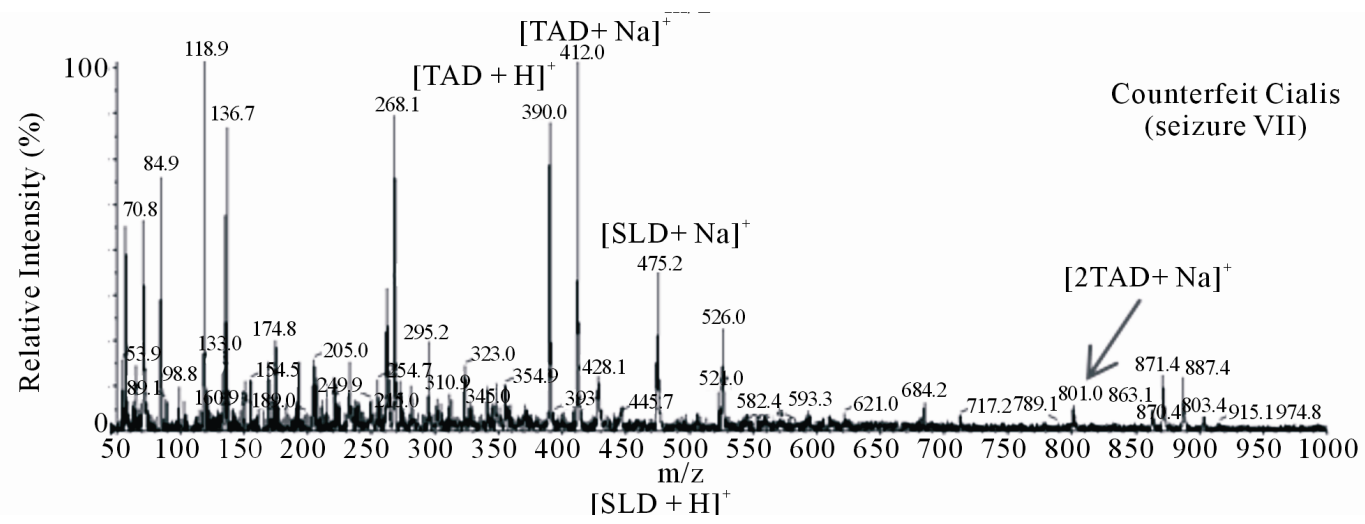

(d) 


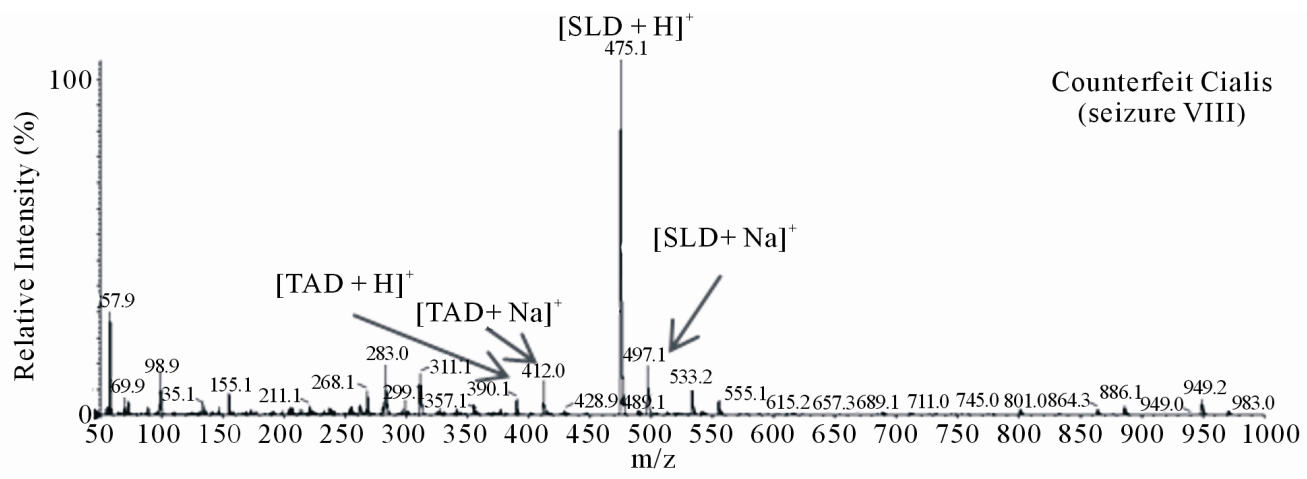

(e)

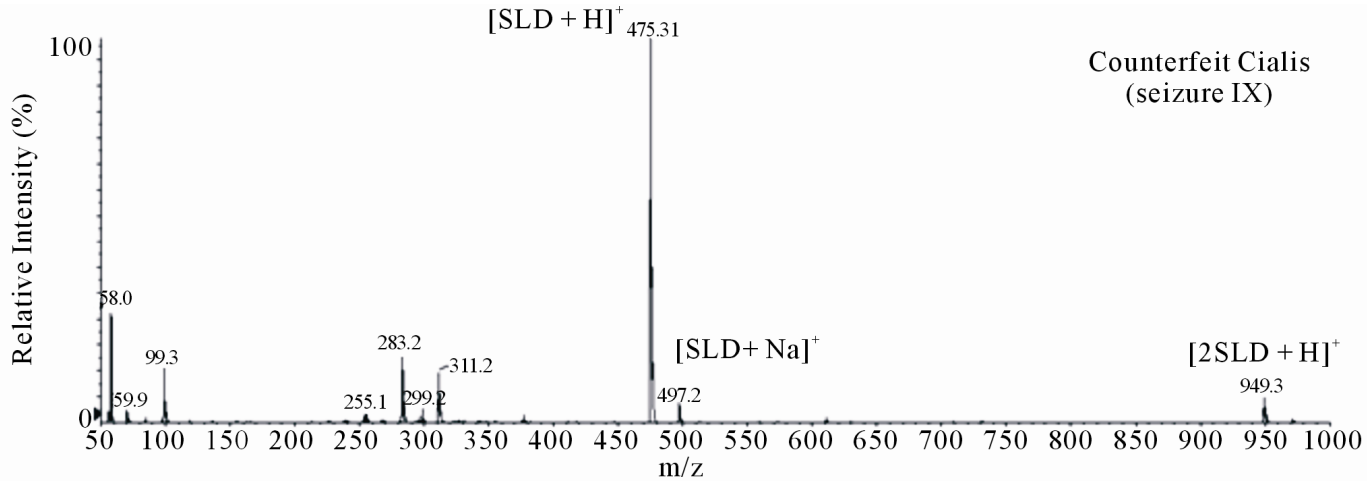

(f)

Figure 3. ESI(+)-MS for authentic and counterfeit Cialis ${ }^{\circledR}$ samples.

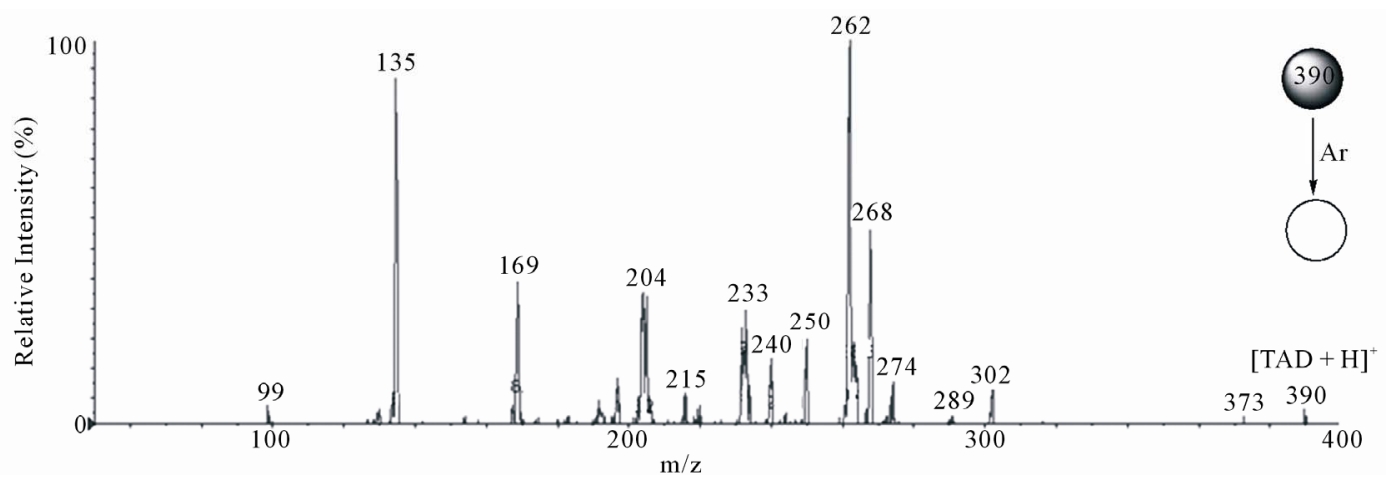

(a)

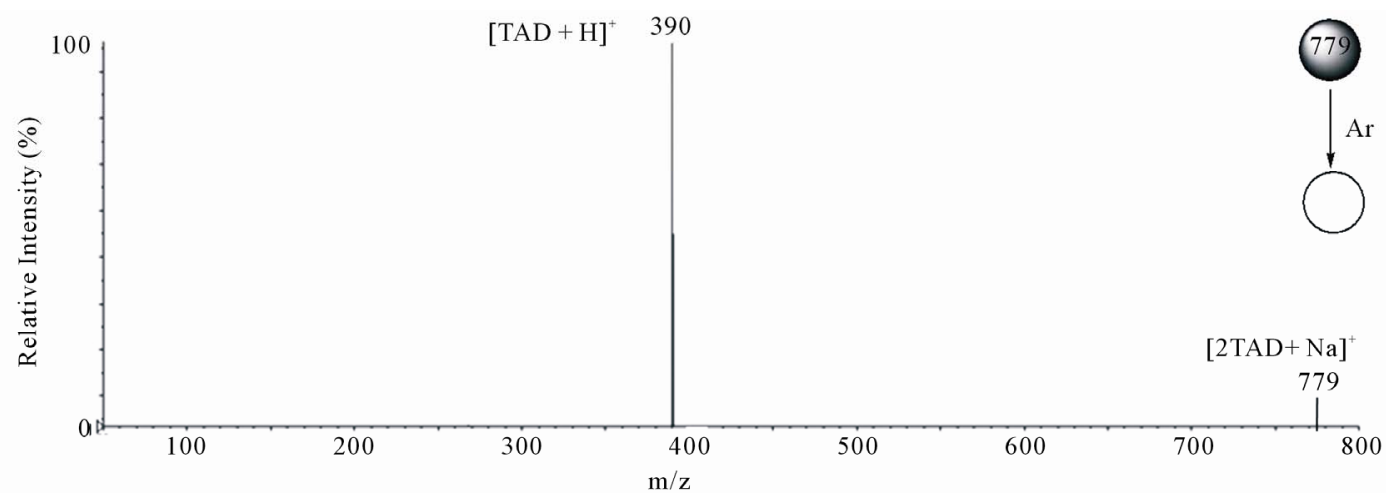

(b) 


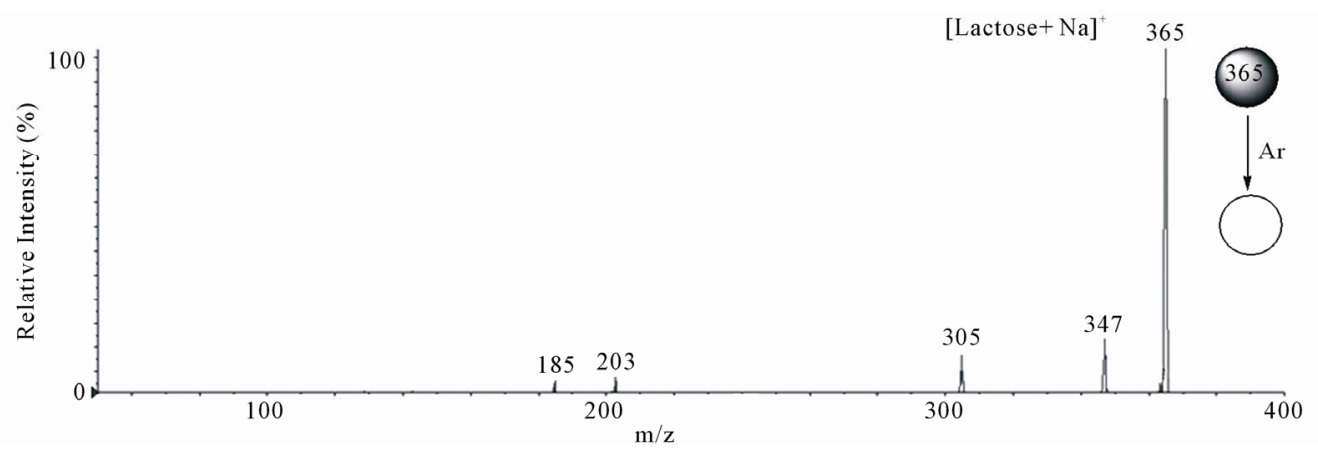

(c)

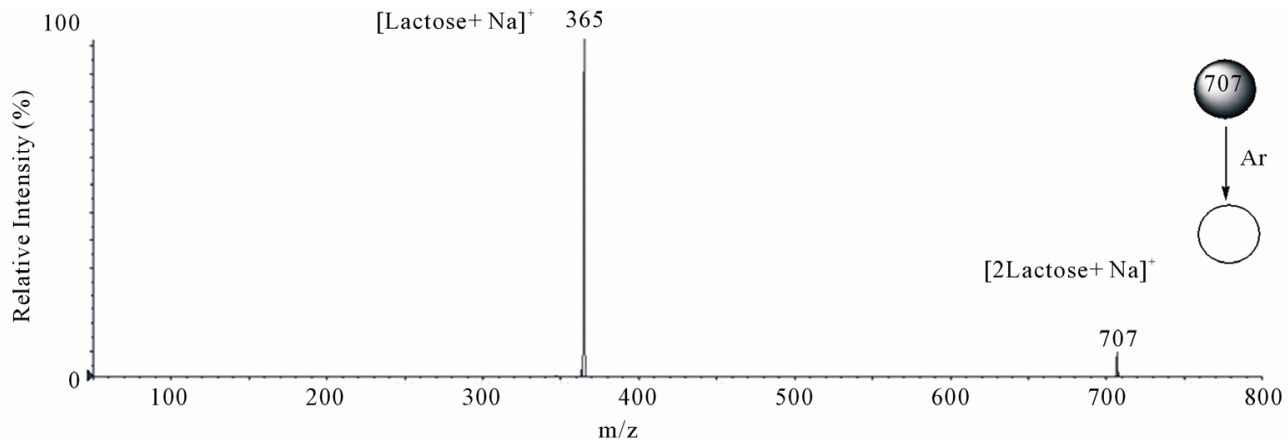

(d)

Figure 4. ESI(+)-MS/MS for some diagnostic ions: (a) [TAD $+\mathbf{H}]^{+}$of $\mathbf{m} / \mathbf{z} 390 ;$ (b) $[2 \mathrm{TAD}+\mathrm{H}]^{+}$of $\mathrm{m} / \mathrm{z}$ 779; (c) $[\mathrm{Lactose}+\mathrm{Na}]^{+}$ of $\mathrm{m} / \mathrm{z} \mathrm{365}$; and (d) $[2 \text { Lactose }+\mathrm{Na}]^{+}$of $\mathrm{m} / \mathbf{z} 707$.

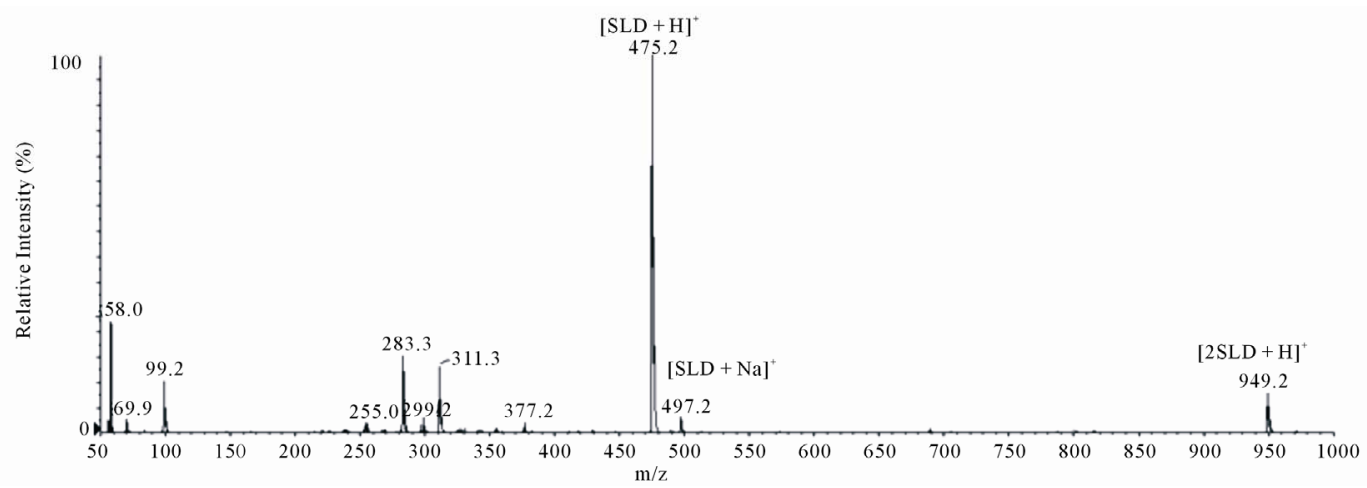

(a)

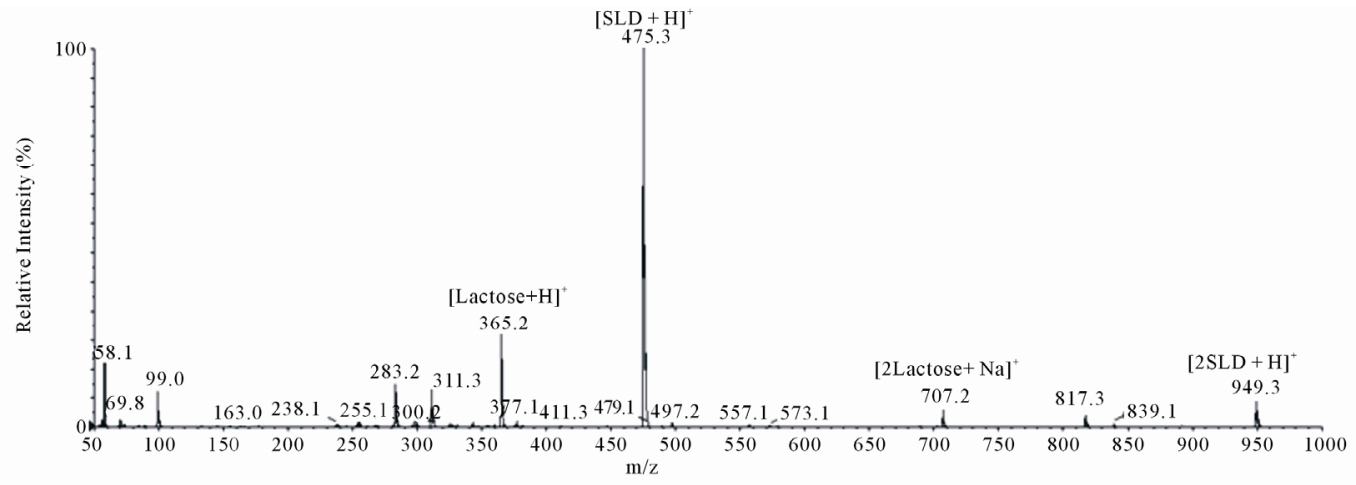

(b)

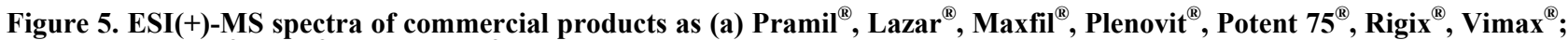
and (b) Pramil $75^{\circledR}, \mathrm{V}-50^{\circledR}$ and Libiden ${ }^{\circledR}$. 
$365,268,262$, and 58 have a greatest influence for the 3PCs loadings.

Authentic Viagra ${ }^{\circledR}$ and counterfeit Viagra samples were both grouped together (group I) in Figure 6 Therefore, a new PCA analysis was performed treating only the samples from group 1 (Figure 7). Note that this procedure provides now two subgroups: group IA (counter-

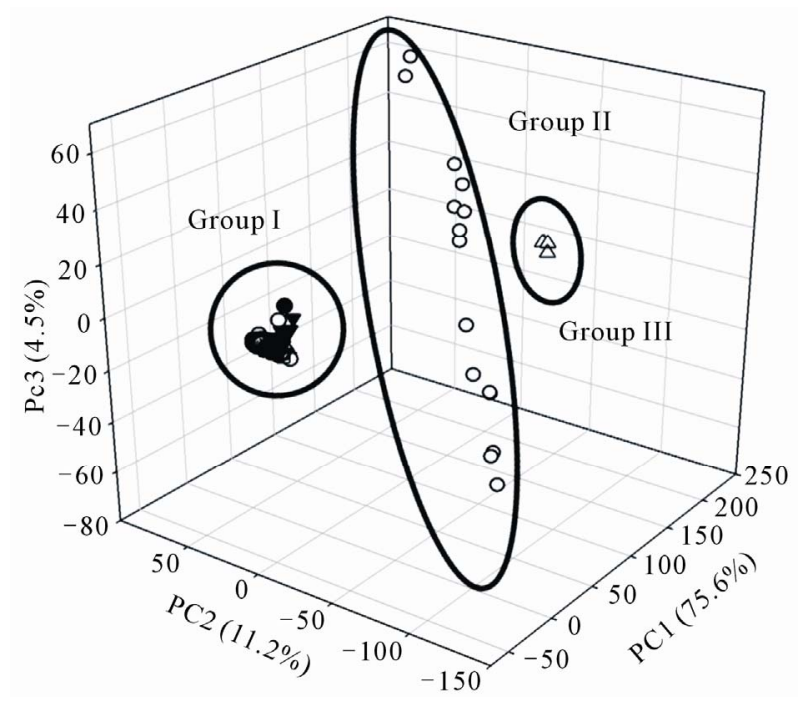

Figure 6. PCA scores plot for ESI-(+)-MS data. The samples are classified into three groups: group I ((口) authentic Viagra ${ }^{\circledR},(\bullet)$ counterfeit Viagra, $(\nabla)$ all commercial SLD samples and some ( ) counterfeit Cialis samples containing the SLD molecule); group II (( ) counterfeit Cialis samples containing the TAD molecule); and group III (( $\Delta)$ authentic Cialis ${ }^{\circledR}$ samples $)$.

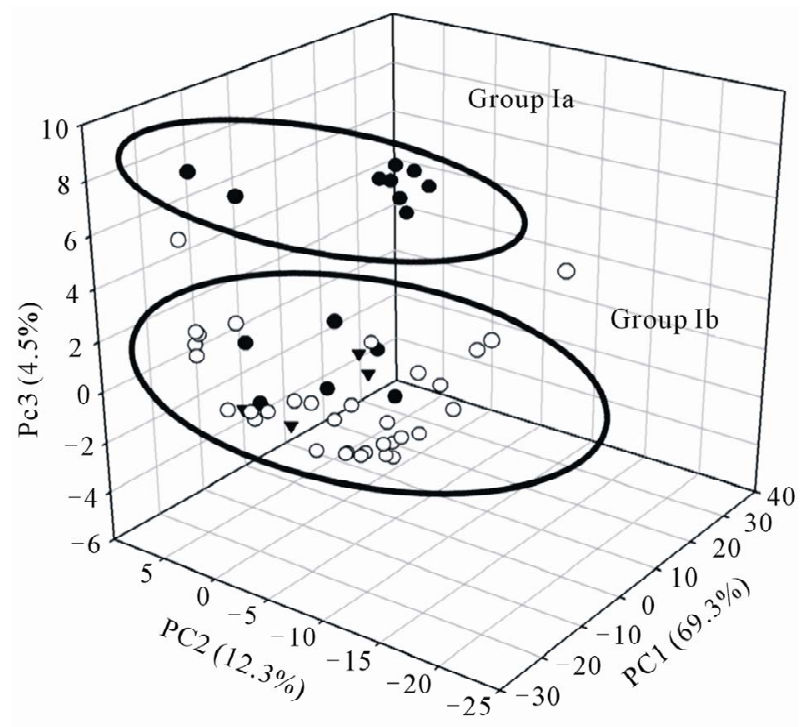

Figure 7. PCA scores plot for ESI-(+)-MS data presents in group $I$. The samples are classified into two groups: group IA ((•) counterfeit Viagra); and group IB $((\nabla)$ authentic Viagra ${ }^{\circledR}$; and $(\odot)$ all commercial SLD samples). feit Viagra samples) and group IB (commercial SLD samples).

\section{Conclusions}

Direct infusion ESI(+)-MS of methanolic extrats of tablets provides a relatively simple and fast screening tool control the quality and to characterize via chemical profiles sildenafil and tadalafil tablets for forensic investigations. This technique requires little sample preparation, minimizing interferences. Principal component analysis (PCA) applied to ESI-MS fingerprint data helps to classify the samples in a more unbiased mode.

\section{Acknowledgements}

The authors thank the Brazilian Federal Police for providing the sildenafil citrate and tadalafil samples. This research has also been generously funded by: FAPESP, FINEP and CNPq.

\section{References}

[1] J. G. Hardman, L. E. Limbird and A. G. Gilman, "The Pharmacological Basis of Therapeutics," 12th Edition, McGraw-Hill, New York, 2010.

[2] I. Wawer, M. Pisklak and Z. Chilmonczyk, "1H, 13C, $15 \mathrm{~N}$ NMR Analysis of Sildenafil Base and Citrate (Viagra) in Solution, Solid State and Pharmaceutical Dosage Forms," Journal of Pharmaceutical Biomedical Analysis, Vol. 38, No. 5, 2005, pp. 865-870. doi:10.1016/j.jpba.2005.01.046

[3] M. J. Vredenbregt, L. Blok-Tip, R. Hoogerbrugge, D. M. Barends and D. de Kaste, "Screening Suspected Counterfeit Viagra and Imitations of Viagra with Near-Infrared Spectroscopy," Journal of Pharmaceutical Biomedical Analysis, Vol. 40, No. 4, 2006, pp. 840-849. doi:10.1016/j.jpba.2005.07.048

[4] J. Maurin, F. Plucinski, A. Mazurek and Z. Fijalek, “The Usefulness of Simple X-Ray Powder Diffraction Analysis for Counterfeit Control-The Viagra Example," Journal of Pharmaceutical Biomedical Analysis, Vol. 43, No. 4, 2007, pp. 1514-1518. doi:10.1016/j.jpba.2006.10.033

[5] M. de Veij, A. Deneckere, P. Vandenabeele, D. de Kaste and L. Moens, "Detection of Counterfeit Viagra R with Raman Spectroscopy," Journal of Pharmaceutical Biomedical Analysis, Vol. 46, No. 2, 2008, pp. 303-309. doi:10.1016/j.jpba.2007.10.021

[6] R. S. Ortiz, M. V. Antunes and R. Linden, "Determinação de Citrato de Sildenafila e de Tadalafila por Cromatografia líquida de Ultraeficiência com Detecção por Arranjo de Diodos (CLUE-DAD)," Química Nova, Vol. 33, No. 2, 2010, pp. 389-393. doi:10.1590/S0100-40422010000200028

[7] D. Zhong, J. Xing, S. Zhang and L. Sun, "Study of the Electrospray Ionization Tandem Mass Spectrometry of 
Sildenafil Derivatives," Rapid Communication Mass Spectrometry, Vol. 16, No. 19, 2002, pp. 1836-1843. doi:10.1002/rcm.794

[8] S. R. Gratza, M. Zeller, D. W. Mincey and C. L. Flurer, "Structural Characterization of Sulfoaildenafil, an Analog of Sildenafil," Journal of Pharmaceutical Biomedical Analysis, Vol. 50, No. 2, 2009, pp. 228-231. doi:10.1016/j.jpba.2009.04.003

[9] P. P. de Souza, L. C. A. de Oliveira, R. R. Catharino, M. N. Eberlin, D. V. Augusti, H. G. L. Siebald and R. Augusti, "Brazilian Cachaça: 'Single Shot' Typification of Fresh Alembic and Industrial Samples via Electrospray Ionization Mass Spectrometry Fingerprinting," Food Chemistry, Vol. 115, No. 3, 2009, pp. 1064-1068. doi:10.1016/j.foodchem.2008.12.026

[10] A. P. B. Gollücke, R. R. Catharino, J. C. de Souza, M. N. Eberlin and D. Q. Tavares, "Evolution of Major Phenolic Components and Radical Scavenging Activity of Grape Juices through Concentration Process and Storage," Food Chemistry, Vol. 112, No. 4, 2009, pp. 868-873. doi:10.1016/j.foodchem.2008.06.060

[11] R. R. Catharino, H. M. S. Milagre, S. A. Saraiva, C. M. Garcia, U. Schuchardt and M. N. Eberlin, "Biodiesel Typification and Quality Control by Direct Infusion Electrospray Ionization Mass Spectrometry Fingerprinting," Energy Fuels, Vol. 21, 2007, pp. 3698-3701. doi:10.1021/ef7003078

[12] A. C. L. Amorim, A. M. C. Hovell, A. C. Pinto, M. N. Eberlin, N. P. Arruda, E. J. Pereira, H. R. Bizzo, R. R. Catharino, Z. B. M. Filho and C. M. Rezende, "Green and Roasted Arabica Coffees Differentiated by Ripeness, Process and Cup Quality via Electrospray Ionization Mass Spectrometry Fingerprinting," Journal of Brazilian Chemistry Society, Vol. 20, No. 2, 2009, pp. 313-321. doi:10.1590/S0103-50532009000200017

[13] L. A. Marques, R. R. Catharino, R. E. Bruns and M. N. Eberlin, "Electrospray Ionization Mass Spectrometry Fingerprinting of Perfumes: Rapid Classification and Counterfeit Detection," Rapid Communication Mass Spectrometry, Vol. 20, No. 24, 2006, pp. 3654-3658. doi: $10.1002 / \mathrm{rcm} .2779$

[14] R. R. Catharino, R. Haddad, L. G. Cabrini, I. B. S. Cunha, A. C. H. F. Sawaya and M. N. Eberlin, "Characterization of Vegetable Oils by Electrospray Ionization Mass Spectrometry Fingerprinting: Classification, Quality, Adulteration, and Aging," Analytical Chemistry, Vol. 77, No. 22, 2005, pp. 7429-7433. doi:10.1021/ac0512507

[15] A. C. H. F. Sawaya, D. M. Tomazela, I. B. S. Cunha, V. S. Bankova, M. C. Marcucci, A. R. Custodio and M. N. Eberlin, "Electrospray Ionization Mass Spectrometry Fingerprinting of Propolis," Analyst, Vol. 129, No. 8, 2004, pp. 739-744. doi:10.1039/b403873h

[16] W. Romão, P. M. Lalli, M. F. Franco, G. Sanvido, N. V. Schwab, R. Lanaro, J. L. Costa, B. D. Sabino, M. I. M. S. Bueno, G. F. de Sa, R. J. Daroda, V. de Souza and M. N. Eberlin, "Chemical Profile of Meta-ChlorophenylpiperaZine (m-CPP) in Ecstasy Tablets by Easy Ambient Sonicspray Ionization, X-Ray Fluorescence, Ion Mobility Mass
Spectrometry and NMR," Analytical and Bioanalytical Chemistry, Vol. 400, No. 9, 2011, pp. 3053-3064. doi:10.1007/s00216-011-4883-9

[17] A. C. H. F. Sawaya, P. V. Abdelnur, M. N. Eberlin, S. Kumazawa, M. R. Ahn, K. S. Bang, N. Nagaraja, V. S. Bankova and H. Afrouzan, "Fingerprinting of Propolis by Easy Ambient Sonic-Spray Ionization Mass Spectrometry," Talanta, Vol. 81, No. 1-2, 2010, pp. 100-108. doi:10.1016/j.talanta.2009.11.043

[18] A. S. Araujo, L. L. da Rocha, D. M. Tomazela, A. C. H. F. Sawaya, R. R. Almeida, R. R. Catharino and M. N. Eberlin, "Electrospray Ionization Mass Spectrometry Fingerprinting of Beer," Analyst, Vol. 130, No. 6, 2005, pp. 884-889. doi:10.1039/b415252b

[19] P. Zou, S. S. Oh, P. Hou, M. Low and H. Koh, "Simultaneous Determination of Synthetic Phosphodiesterase-5 Inhibitors Found in a Dietary Supplement and Pre-Mixed Bulk Powders for Dietary Supplements Using High-Performance Liquid Chromatography with Diode Array Detection and Liquid Chromatography-Electrospray Ionization Tandem Mass Spectrometry," Journal of Chromatography A, Vol. 1104, No. 1-2, 2006, pp. 113-122. doi:10.1016/j.chroma.2005.11.103

[20] L. Blok-Tip, B. Zomer, F. Bakker, K. D. Hartog, M. Hamzink, J. Ten Hove, M. Vredenbregt and D. de Kaste, "Structure Elucidation of Sildenafil Analogues in Herbal Products," Food Additive and Contamination, Vol. 21, No. 8, 2004, pp. 737-748. doi:10.1080/02652030412331272467

[21] S. Ahn, J. Y. Hong, M. K. Hong, Y. P. Jang, M. S. Oh, J. H. Jung and J. Hong, "Structural Determination of Sildenafil and Its Analogues in Dietary Supplements by Fastatom Bombardment Collision-Induced Dissociation Tandem Mass Spectrometry," Rapid Communication Mass Spectrometry, Vol. 23, No. 19, 2009, pp. 3158-3166. doi: $10.1002 / \mathrm{rcm} .4238$

[22] L Nyadong, G. A. Harris, S. Balayssac, A. S. Galhena, M. Malet-Martino, R. Martino, R. M. Parry, M. D. Wang, F. M. Fernández and V. Gilard, "Combining Two-Dimensional Diffusion-Ordered Nuclear Magnetic Resonance Spectroscopy, Imaging Desorption Electrospray Ionization Mass Spectrometry, and Direct Analysis in RealTime Mass Spectrometry for the Integral Investigation of Counterfeit Pharmaceuticals," Analytical Chemistry, Vol. 81, No. 12, 2009, pp. 4803-4812. doi:10.1021/ac900384j

[23] S. Singh, B. Prasad, A. Savaliya, R. Shah, V. Gohil and A. Kaur, "Strategies for Characterizing Sildenafil, Vardenafil, Tadalafil and Their Analogues in Herbal Dietary Supplements, and Detecting Counterfeit Products Containing These Drugs," Trends Analytical Chemistry, Vol. 28, No. 1, 2009, pp. 13-28. doi:10.1016/j.trac.2008.09.004

[24] B. J. Venhuis, D. M. Barends, M. E. Zwaagstra and D. de Kaste, "Recent Developments in Counterfeits and Imitations of Viagra, Cialis and Levitra: A 2005-2006 Update," National Institute for Public Health and the Environment (RIVM), Bilthoven, 2007. 